(c) American Dairy Science Association, 2004.

\title{
Comparison of Pilot-Scale and Rapid Visco Analyzer Process Cheese Manufacture
}

\author{
R. Kapoor, P. Lehtola, and L. E. Metzger \\ MN-SD Dairy Foods Research Center, Department of Food Science and Nutrition, \\ University of Minnesota, St. Paul 55108
}

\begin{abstract}
Numerous formulation and processing parameters influence the functionality of process cheese. A smallscale manufacturing and analysis method could be used to evaluate the influence of formulation parameters and processing conditions on the functionality of process cheese. The objective of this study was to compare process cheese produced on a small-scale ( $25 \mathrm{~g})$ in a Rapid Visco Analyzer (RVA) to process cheese produced on a pilot-scale $(4.5 \mathrm{~kg})$ in a Blentech twin-screw pilot-scale cooker (BTS). Three replicates of pasteurized process cheese (PC) and pasteurized process cheese food (PCF) were produced in an RVA and in a BTS. Texture profile analysis (TPA) and the RVA melt test were performed on all PC and PCF produced. There was a significant replication effect on TPA-hardness and hot apparent viscosity of the PC and PCF produced in the RVA and the BTS. The PC and PCF produced in the RVA had significantly higher TPA-hardness and hot apparent viscosity compared with $\mathrm{PC}$ and PCF produced in the BTS. The RVA manufacturing time (short vs. long) did not have a significant effect on TPA-hardness values for PC or PCF. However, the long manufacturing time significantly increased hot apparent viscosity for PC and PCF. The RVA was successfully used to manufacture process cheeses; however, differences in the manufacturing profiles and type of cooker influenced the functional properties of the process cheese.
\end{abstract}

(Key words: process cheese, rapid visco analyzer)

Abbreviation key: BTS = Blentech twin-screw pilotscale cooker, $\mathbf{P C}=$ pasteurized process cheese, $\mathbf{P C F}=$ pasteurized process cheese food, $\mathbf{R D}=$ relative deviation, RSD = relative standard deviation, RVA = Rapid Visco Analyzer, RVA-LT = Rapid Visco Analyzer - long manufacturing time, RVA-ST = Rapid Visco Analyzer short manufacturing time, TPA = texture profile analysis.

Received January 13, 2004.

Accepted June 15, 2004.

Corresponding author: L. E. Metzger; e-mail: lmetzger@umn.edu.

\section{INTRODUCTION}

Process cheese is a generic term used to describe 3 categories of cheese. These categories are pasteurized process cheese (PC), pasteurized process cheese food (PCF), and pasteurized process cheese spread (FDA, 2003). According to the Food and Drug Administration (2003), these 3 categories differ in requirements for minimum fat content on DM basis, the maximum allowed moisture content, and the quantity and number of optional ingredients that can be used. Functional characteristics such as meltability and textural properties are important attributes that influence the quality and end-use of process cheese (Zehren and Nusbaum, 2000; Guinee, 2002; Lucey et al., 2003). Process cheese is used in several forms (e.g., slices, blocks, shreds, and sauces) and as an ingredient in numerous products. Consequently, the required functional characteristics (unmelted texture and melting properties) are unique for each process cheese end-use application.

Researchers have highlighted the importance of the effect of formulation and processing parameters on the final functional properties of process cheese. The type and amount of natural cheese, emulsifying salts, and other ingredients used when formulating process cheese have an influence on its functional properties (Thomas, 1973; Gupta et al., 1984; Caric et al., 1985; Zehren and Nusbaum, 2000). Processing parameters such as cook temperature, cook time, and the amount of shear during manufacture play a major role in controlling the emulsion formation and the resulting functional properties of process cheese (Rayan et al., 1980; Berger et al., 1998; Glenn et al., 2003). Studies by Rayan et al. (1980) on process cheese manufactured with 4 different emulsifying salts showed that, as the processing time was increased, the meltability of the resulting process cheese decreased, and its firmness increased. Glenn et al. (2003) subjected process cheese to different processing conditions involving shear rate and processing time/temperature. Their studies indicated that different processing conditions influenced the meltability of process cheese. Researchers have indicated that the rate at which the cooked product is cooled influences the meltability and firmness of process 
cheese (Thomas, 1973; Piska and Štětina, 2003). Moreover, the intrinsic parameters of the final product, such as fat (Hong, 1990), moisture (Hong, 1989), $\mathrm{pH}$ (Lee and Klostmeyer, 2001), relative casein content (the amount of intact casein), calcium, and phosphate level (Vakaleris et al., 1962; Sood et al., 1979; Piska and Stětina, 2003) affect the functional properties of process cheese. Shimp (1985) provides a comprehensive description of factors influencing process cheese properties.

Because of the numerous formulation and processing parameters that influence the functional properties of process cheese, manufacturers often struggle to produce process cheese with targeted product characteristics. Therefore, a small-scale manufacture and analysis system for process cheese would facilitate a rapid and inexpensive assessment of the effect of formulation and processing condition on product characteristics.

To address this problem, a small-scale system for process cheese was developed, wherein 25- to $30-\mathrm{g}$ batches of process cheese could be produced using a Rapid Visco Analyzer (RVA) (Metzger et al., 2002). The RVA is a computer-integrated instrument developed by Newport Scientific (Warriewood, Australia) to determine the viscous properties of cooked starch, grain, batters, and other foods. The RVA can measure apparent viscosity over variable conditions of shear and temperature as defined by the operator. Consequently, the RVA is capable of simulating the temperature and shear profiles used to make process cheese on a large scale. Using methodology described by Metzger et al. (2003), after manufacture in the RVA, the molten processed cheese was transferred into cylindrical molds and cooled. Texture profile analysis (TPA) was performed on the cold process cheese cylinder to measure its unmelted textural properties such as TPA-hardness, which describes the firmness of the cheese (Breene, 1975). The process cheese was then ground and remelted in the RVA to assess its melting properties, such as hot apparent viscosity, which is a measure of how well a cheese flows at a fixed temperature (Rosenberg and Metzger, 2003). These studies have indicated the possibility of using the RVA for the small-scale production and subsequent analysis of process cheese.

The objective of our study was to compare the functional properties of process cheese produced with the RVA on a small-scale to cheese produced with a pilotscale process cheese cooker. The present study also evaluated the effect of manufacturing time (using the RVA) on process cheese functional properties.

\section{MATERIALS AND METHODS}

\section{Experimental Design}

Three replicates of $\mathrm{PC}$ and $\mathrm{PCF}$, with each replicate using a different young and aged natural cheese, were
Table 1. The range of the amount of different ingredients used for formulating process cheese (PC) and process cheese food (PCF) in 3 replicates.

\begin{tabular}{lccc}
\hline Ingredients, \% & PC & PCF \\
\hline Young cheese (<1mo) & 50.3 to 54.1 & 55.8 to 60.1 \\
Aged cheese (6-12 mo) & 25.9 to 30.0 & 10.0 to 16.7 \\
Dried cream & 5.8 & $\ldots$ & \\
Butter oil (anhydrous) & 1.4 to 2.7 & 0.8 to 2.2 \\
Nonfat dried milk & $\ldots$ & & 3.0 \\
Whey powder & $\ldots$ & 5.0 & \\
Enzyme modified cheese & 0.4 & 0.4 & \\
Sodium phosphate, dibasic & 2.25 & 2.5 & \\
Sodium citrate & $\ldots .4$ to 0.6 & 0.5 to 0.7 \\
Salt & 0.4 to 9.2 & 15.9 to 16.7 \\
Water & 100.0 & 100.0 & \\
Total & & &
\end{tabular}

produced on 3 different days. Each replicate was subjected to 3 manufacturing treatments, including RVAshort manufacturing time (RVA-ST), RVA-long manufacturing time (RVA-LT), and Blentech twin-screw pilot-scale cooker (BTS) (Blentech Corporation, Rohnert Park, CA). Each replicate of PC and PCF was produced in triplicate for RVA-ST and RVA-LT treatments, and in duplicate for the BTS treatment. One of the replicates for the RVA-ST and RVA-LT treatments was produced in quadruplicate and the extra sample was used for moisture analysis.

\section{Process Cheese Formulation}

The formulations for all replicates were developed using Techwizard, an Excel-based formulation software program (Metzger, 2003) provided by Owl Software (Lancaster, PA). The detailed ingredient blend and formulations for PC and PCF are shown in Table 1. The formulation software was used to balance moisture, fat, salt, whey protein, and lactose to $39.5,30.0,2.0,0.5$, and $2.3 \%$, respectively, for $\mathrm{PC}$, and $43.5,35.0,2.0,1.1$, and $5.8 \%$, respectively, for PCF. Young and aged cheeses used in the ingredient blend were obtained from commercial cheese facilities. A different young and aged cheese was used for each replicate. The young cheeses were less than 1 mo old, and the aged cheeses were 6 to 12 mo old. The emulsifying salts used were sodium phosphate (dibasic) (Astaris LLC, St. Louis, MO) for PC, and trisodium citrate (duohydrate) (Archer Daniels Midland Company, Decatur, IL) for PCF. Other ingredients included nonfat dried milk (low heat) (Dairy America, Fresno, CA), anhydrous butter oil (MidAmerica farms, Springfield, MO), sweet whey powder (Bongards Creameries, Bongards, MN), and enzyme-modified cheese (Land O' Lakes Inc., St. Paul, MN). Dried cream was prepared by standardizing butter oil to $40 \%$ fat with nonfat dried milk. 


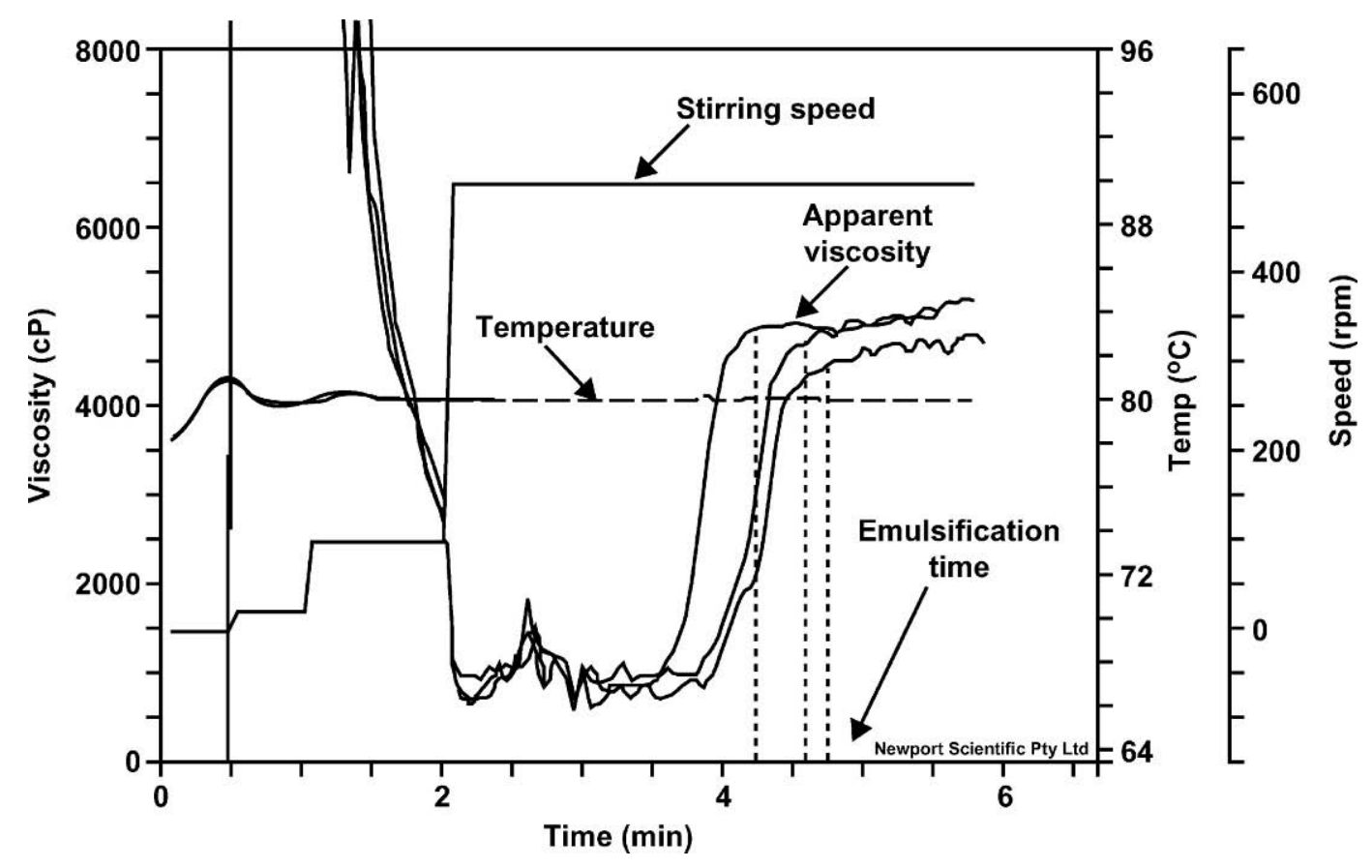

Figure 1. Triplicate manufacture of process cheese (PC) replicate \# 1 using the Rapid Visco Analyzer (RVA)-LT manufacturing profile. The dotted lines indicate the emulsification time on the x-axis. The stirring speed, temperature, and apparent viscosity are identified on the figure.

\section{Process Cheese Manufacture}

RVA small-scale manufacture. A preblend of all the ingredients ( $25 \mathrm{~g}$ total) was prepared by weighing each of the dry ingredients and water into the RVA canister and shaking the canister to mix the ingredients. This was followed by addition of the anhydrous butter oil. Additional water $(0.3 \mathrm{~g})$ was added to the preblend to compensate for moisture loss during manufacture (Metzger et al., 2002). During manufacture, the temperature of the RVA canister was maintained at $80^{\circ} \mathrm{C}$. Stirring speed was increased from 0 to $500 \mathrm{rpm}$ over $2 \mathrm{~min}$, and then held at $500 \mathrm{rpm}$ until the end of the manufacturing process. The manufacture times were divided into short (RVA-ST) and long (RVA-LT) by stopping the RVA at $1 \mathrm{~min}$ and $2 \mathrm{~min}$, respectively, once an increase in viscosity was observed after the stirring speed reached $500 \mathrm{rpm}$ (Figures 1 and 2). The time at which an increase in viscosity was observed was recorded as the time of emulsification for all cheeses made using the RVA. The final weight of the canister was recorded immediately after manufacture and the weight loss (moisture loss) was calculated. After manufacture, the process cheeses were transferred to copper cylinders $(20 \times 30 \mathrm{~mm}$, diameter $\times$ height $)$. The cylinders were sealed with plastic wrap and transferred to the cold room $\left(4^{\circ} \mathrm{C}\right)$ after $15 \mathrm{~min}$. The cylinders were stored at $4^{\circ} \mathrm{C}$ until further analysis was completed.
Pilot-plant manufacture. A preblend of all the ingredients was prepared $(4.5 \mathrm{~kg})$ in the Blentech twinscrew cooker blender by mixing at $75 \mathrm{rpm}$ for $3 \mathrm{~min}$ at room temperature. The temperature of the preblend was then increased to $80^{\circ} \mathrm{C}$ over $3 \mathrm{~min}$ and held for an additional $4 \mathrm{~min}$. The auger speed was $120 \mathrm{rpm}$ for PC and $140 \mathrm{rpm}$ for PCF during the heating and holding periods of the manufacturing process. These conditions were based on the recommendations of Kosikowski and Mistry (1997). One-kilogram boxes were filled with the molten process cheeses and transferred to a cold room $\left(4^{\circ} \mathrm{C}\right)$ after $15 \mathrm{~min}$. The cooked process cheeses were stored at $4^{\circ} \mathrm{C}$ until further analysis was completed.

\section{Chemical Analyses}

Due to limitations in the sample size of cheese manufactured in the RVA, complete chemical analysis was not performed; however, moisture content for the RVAprocess cheeses was measured. Moisture contents of the BTS process cheese and both RVA process cheeses (one replicate each) were analyzed using a vacuum oven, as described by Bradley and Vanderwarn (2001). Fat content of the BTS process cheese was determined using the Mojonnier method (Atherton and Newlander, 1977). Salt content of the BTS process cheese was measured using a Corning Chloride Analyzer 926; and $\mathrm{pH}$ was measured with a Corning $\mathrm{pH}$ /ion meter model 450 


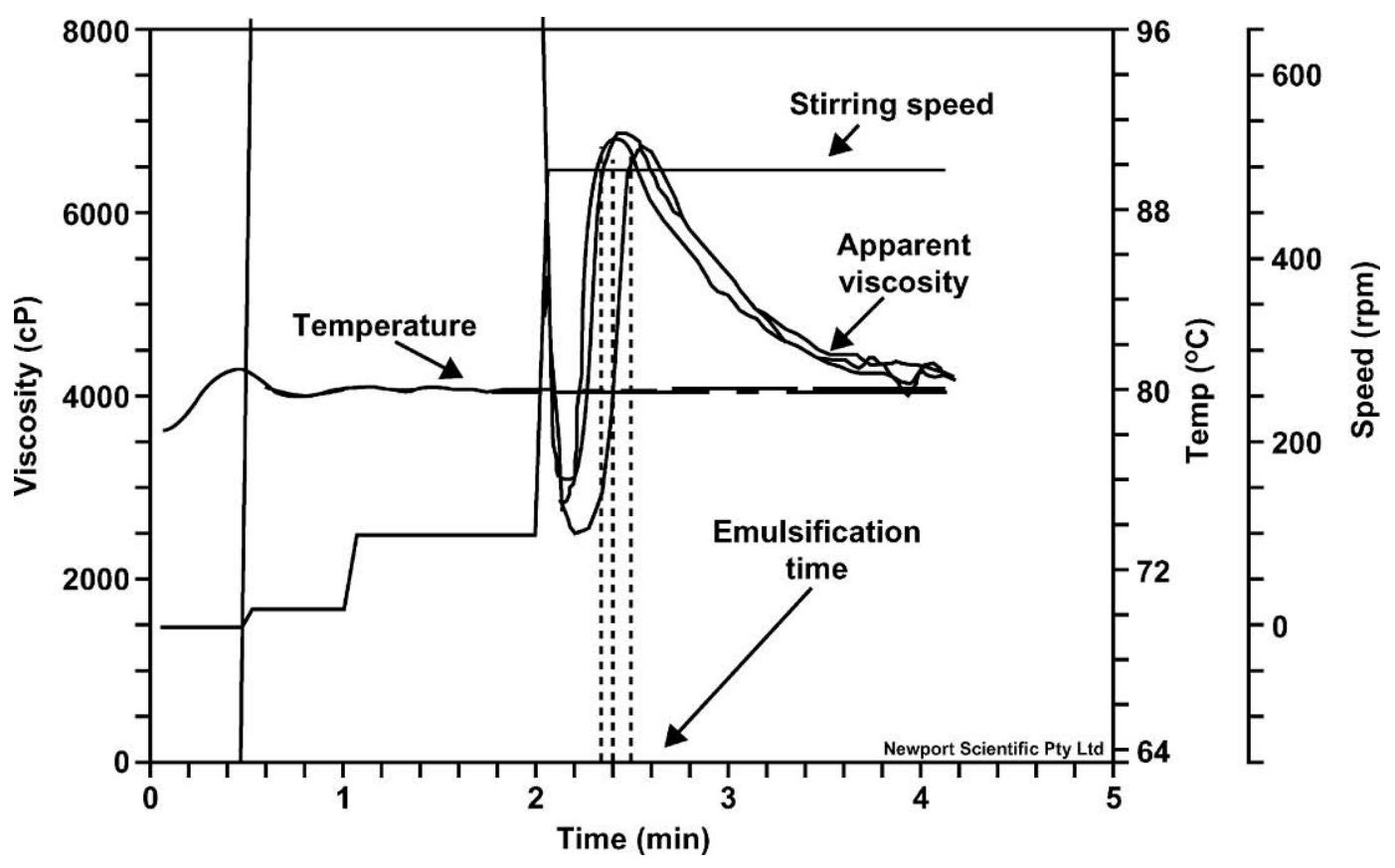

Figure 2. Triplicate manufacture of process cheese food (PCF) replicate \# 1 using the Rapid Visco Analyzer (RVA)-LT manufacturing profile. The dotted lines indicate the emulsification time on the x-axis. The stirring speed, temperature, and apparent viscosity are identified on the figure.

(Corning Glass Works, Medfield, MA) with a Sentron streamline $\mathrm{pH}$ probe (Sentron, Gig Harbor, WA).

\section{Functional Analyses}

RVA melt test. The RVA was used to determine the apparent viscosity of PC and PCF from all 3 manufacturing processes during a heating, holding, and cooling profile, as described by Rosenberg et al. (2002). In the RVA melt test, the canister temperature was raised from $25^{\circ} \mathrm{C}$ over 5 min to a peak temperature of $85^{\circ} \mathrm{C}$, held for $3 \mathrm{~min}$ at the peak temperature, and cooled to $25^{\circ} \mathrm{C}$ over $6 \mathrm{~min}$. The stirring speed was held at $0 \mathrm{rpm}$ for $30 \mathrm{~s}, 20 \mathrm{rpm}$ for $30 \mathrm{~s}, 100 \mathrm{rpm}$ for $1 \mathrm{~min}$, and 300 rpm for the remainder of the test. During stirring, the apparent viscosity was continuously measured. The minimum apparent viscosity during the holding period was collected from the apparent viscosity vs. time curve and is referred to as hot apparent viscosity (Rosenberg and Metzger, 2003).

TPA-hardness. For BTS process cheese, 5 representative samples of $\mathrm{PC}$ and $\mathrm{PCF}$ within each replicate were cut into cylinders $20 \mathrm{~mm}$ in diameter $\times 20 \mathrm{~mm}$ high using a cork borer. The samples were wrapped in plastic wrap and tempered at $4^{\circ} \mathrm{C}$ for $30 \mathrm{~min}$ before the test. For RVA-ST and RVA-LT batches, the cylinders of cheese $(20 \times 30 \mathrm{~mm})$ were removed from the copper molds and cut to a height of $20 \mathrm{~mm}$. Texture profile analysis was performed using a TA.XT2 Texture Analyzer (Texture Technologies Corp., Scarsdale, NY/Stable Microsystems, Godalming, UK) as described by Drake et al. (1999). The test conditions were: Uniaxial double bite compression, $50-\mathrm{mm}$ diameter cylindrical flat probe (TA-25); compression, 80\%; crosshead speed, $0.8 \mathrm{~mm} / \mathrm{s}$. Process cheese was analyzed for TPA-hardness as described by Breene (1975).

\section{Statistical Analysis}

A randomized complete block design with 3 manufacturing treatments (RVA-ST, RVA-LT, and BTS) was used for the statistical analysis of the functional properties and moisture loss of PC and PCF individually. The replicates (each of which was manufactured on a different day) were treated as the blocks of the design. Type III ANOVA was performed to obtain the mean squares and the $P$ values using Macanova (version 4.12, School of Statistics, University of Minnesota, St. Paul, MN). This was done to account for the unbalanced data among the 3 treatments. The comparisons were made at a 0.05 level of significance and the results were considered significant at $P<0.05$. Relative standard deviations (RSD) of the time of emulsification, functionality values for the 2 RVA treatments, and relative deviations (RD) from the mean of the functionality values in the BTS treatment within each replicate were calcu- 
lated to compare the repeatability of the RVA and BTS for process cheese manufacture using the formula: RSD or $\mathrm{RD}=($ standard deviation $/$ mean $) \times 100$.

\section{RESULTS}

\section{Composition of Process Cheese}

The mean values for moisture, fat, salt, and $\mathrm{pH}$ were $39.7,31.2,1.97 \%$, and 5.67, respectively, for the BTSprocessed $\mathrm{PC}$, and $43.3,25.3,2.0 \%$, and 5.61, respectively, for the BTS PCF. The moisture content of PC using the RVA was 39.3 and $39.2 \%$, respectively, for the RVA-ST and RVA-LT process, and the moisture content of PCF was 43.4 and $43.2 \%$, respectively, for the RVA-ST and RVA-LT process. All of the process cheese met the legal standards of identity specified by the Food and Drug Administration (2003).

\section{Weight Loss in RVA Process Cheeses}

The mean weight loss of the 3 replicates during manufacture in the RVA was 0.22 and $0.26 \mathrm{~g}$ for PC, and 0.21 and $0.25 \mathrm{~g}$ for PCF, for RVA-ST and RVA-LT treatments, respectively. There was a significant difference $(P<0.05)$ in the weight loss between RVA-ST and RVALT for PC and PCF. The percentage weight loss in the RVA amounted to approximately $0.8 \%$ for RVA-ST and approximately $1.0 \%$ for RVA-LT for both PC and PCF. Because there was no loss in product before or after manufacture in the RVA, the weight loss during manufacture can be used as an indicator of moisture loss during manufacture. However, some moisture condenses on the sides of the canister and on the stirring paddle that is not measured as weight loss. Moreover, because the moisture values measured for one of the RVA replicates (as indicated earlier) were very close to the targeted moisture values for PC and PCF, the addition of approximately $0.3 \mathrm{~g}$ of additional water to the process cheese batches manufactured in the RVA, as specified by Metzger et al. (2002), was able to overcome the moisture loss during processing in the RVA. The moisture loss of the BTS process cheeses was not measured because BTS processing was done in a sealed cooker.

\section{Time of Emulsification During Manufacture and Final Functional Properties}

Process cheese. The mean values and RSD/RD of the time of emulsification during manufacture (RVA) and the final functional properties of PC manufactured by RVA-ST, RVA-LT, and BTS, including TPA-hardness and hot apparent viscosity, are indicated in Table
2. The overall mean of 3 replicates for each of the 3 treatments is indicated in Table 2. The mean squares and the $P$ values for the functional properties with regards to PC are shown in Table 3. The mean of all the replicates for TPA-hardness and hot apparent viscosity of PC produced with the BTS were significantly lower than PC produced with the RVA-ST and RVA-LT treatments $(P<0.05)$. Within the 2 RVA treatments, there was no significant difference in the TPA-hardness values between RVA-ST and RVA-LT, whereas hot apparent viscosity of the PC produced in RVA-LT was significantly higher than PC produced using RVA-ST. There was a significant replication effect on all the functional properties (Table 3 ).

Process cheese food. The mean values and RSD/RD of the time of emulsification during manufacture (RVA) and the final functional properties of PCF manufactured by RVA-ST, RVA-LT, and BTS, including TPAhardness and hot apparent viscosity, are indicated in Table 4. The overall mean of 3 replicates for each of the 3 treatments is also presented in Table 4 . The mean squares and the $P$ values for functional properties of PCF are shown in Table 3. The overall mean of the replicates for TPA-hardness and hot apparent viscosity of PCF produced with BTS were significantly lower than PCF produced with the RVA-ST and RVA-LT treatments. Within the 2 RVA treatments, there was no significant difference in the TPA-hardness values, whereas hot apparent viscosity of the PCF produced in RVA-LT was significantly higher than PCF produced using RVA-ST. There was a significant replication effect on all of the functional properties (Table 3).

\section{DISCUSSION}

\section{Interpretation of Process Cheese Manufacture in the RVA}

Significance of time of emulsification. For RVAprocess cheese, a sudden increase in apparent viscosity (monitored using the RVA apparent viscosity curve) is observed during manufacture (Figures 1 and 2). This increase in the viscosity was used as an indicator of emulsion formation and is noted as the time of emulsification (Tables 2 and 4). During process cheese manufacture, the addition of emulsifying salts improves the emulsification properties of caseins by disrupting the calcium-phosphate linked protein network present in natural cheese (Gupta et al., 1984; Caric et al., 1985; Berger et al., 1998). This disruption of the natural protein network results in the exposure of hydrophilic and hydrophobic sections of the individual caseins. Subsequently, when shear and heat are applied, the disrupted caseins become hydrated due to hydrophilic interactions with the aqueous phase, and they interact with 
Table 2. Mean, relative standard deviation (RSD) from the mean ( $\mathrm{n}=3$ for RVA-ST and RVA-LT), and relative deviation (RD) from the mean ( $\mathrm{n}=2$ for BTS) values of the time of emulsification and the functional properties of process cheese.

\begin{tabular}{|c|c|c|c|c|c|c|c|c|c|c|c|c|c|c|c|c|}
\hline \multirow{2}{*}{ Replicate no. } & \multicolumn{4}{|c|}{$\begin{array}{c}\text { Time of emulsification } \\
(\mathrm{min})\end{array}$} & \multicolumn{6}{|c|}{ TPA-hardness, $\mathrm{N}$} & \multicolumn{6}{|c|}{ Hot apparent viscosity, $\mathrm{cP}$} \\
\hline & \multicolumn{2}{|c|}{$\mathrm{RVA}^{-\mathrm{ST}^{1}}$} & \multicolumn{2}{|c|}{$\mathrm{RVA}^{-\mathrm{LT}^{2}}$} & \multicolumn{2}{|c|}{ RVA-ST } & \multicolumn{2}{|c|}{ RVA-LT } & \multicolumn{2}{|c|}{$\mathrm{BTS}^{3}$} & \multicolumn{2}{|c|}{ RVA-ST } & \multicolumn{2}{|c|}{ RVA-LT } & \multicolumn{2}{|c|}{ BTS } \\
\hline 1 & 3.2 & 11.27 & 3.4 & 5.09 & 135 & 4.12 & 139 & 5.61 & 100 & 0.60 & 1058 & 13.16 & 1210 & 5.72 & 651 & 10.97 \\
\hline 2 & 3.2 & 12.88 & 3.8 & 5.52 & 194 & 0.89 & 184 & 9.92 & 139 & 16.27 & 772 & 11.29 & 871 & 15.40 & 710 & 11.75 \\
\hline 3 & 3.8 & 5.52 & 3.2 & 12.88 & 197 & 0.50 & 213 & 4.47 & 155 & 0.91 & 891 & 10.41 & 1012 & 4.29 & 819 & 3.28 \\
\hline
\end{tabular}

a,b,c Means with same superscript are not significantly different at $P>0.05$.

${ }^{1}$ RVA-ST = Rapid visco analyzer-short manufacturing time.

${ }^{2}$ RVA-LT $=$ Rapid visco analyzer-long manufacturing time.

${ }^{3} \mathrm{BTS}=$ Blentech twin-screw pilot-scale cooker.

the fat phase via hydrophobic interactions (Marchesseau and Cuq, 1995; Ennis et al., 1998; Lee et al., 2003). These interactions cause the fat phase to be emulsified by a uniform closely-knit protein network. This phenomenon causes the observed increase in the apparent viscosity of cheese as monitored in the RVA during process cheese manufacture. Lee et al. (2003) provides a detailed description of this phenomenon.

Relationship between time of emulsification and functional properties of the final product. The RSD values for TPA-hardness and hot apparent viscosity for the 3 replicates of PC and PCF are shown in Tables 2 and 4, respectively. The RSD for TPA-hardness and hot apparent viscosity values were lower in PCF than in PC for all 3 manufacturing treatments. This might be attributed to less variability in the time of emulsification, and a more consistent viscosity curve for PCF compared with PC (Figures 1 and 2). We theorize that the amount of shear applied after an emulsion has been created, as well as the total processing time, influences the final functional properties of process cheese. Because the variability in the time of emulsification was larger (and the total processing time longer) in PC compared with $\mathrm{PCF}$, more variability in the functional properties was observed.

\section{Comparison of RVA and BTS Process Cheese}

\section{Effect of natural cheese used in the formulation.}

Statistical analysis (Table 3) revealed a significant replication effect on TPA-hardness and hot apparent viscosity for PC and PCF. All the replicates used in this study were balanced for moisture, fat, salt, whey protein, and lactose. However, different young and aged natural cheeses were used for each replicate. Consequently, the observed replication effect on the functional properties may be due to variations in the properties of the natural cheese used in each replicate (e.g., calcium and phosphate content, relative casein content) (Berger et al., 1998; Zehren and Nusbaum, 2000).

Although the TPA-hardness of PC and PCF within each replicate was higher for the RVA treatments than for BTS treatments, it followed a similar trend for each of the 3 PC replicates and for 2 of the PCF replicates.

Table 3. Mean squares and $P$-values (in parentheses) of the functional properties for process cheese (PC) and process cheese food (PCF).

\begin{tabular}{|c|c|c|c|c|c|}
\hline \multirow[b]{2}{*}{ Factors } & \multirow[b]{2}{*}{$\mathrm{df}$} & \multicolumn{2}{|c|}{$\mathrm{PC}$} & \multicolumn{2}{|c|}{$\mathrm{PCF}$} \\
\hline & & $\begin{array}{l}\text { Hot apparent } \\
\text { viscosity }\end{array}$ & TPA-hardness & $\begin{array}{l}\text { Hot apparent } \\
\text { viscosity }\end{array}$ & TPA-hardness \\
\hline Replicate $^{1}$ & 2 & $\begin{array}{l}86,134 \\
\quad(<0.01)\end{array}$ & $\begin{array}{l}9127.1 \\
\quad(<0.01)\end{array}$ & $\begin{array}{l}8267.8 \\
(<0.01)\end{array}$ & $\begin{array}{l}857.28 \\
(<0.01)\end{array}$ \\
\hline Treatment $^{2}$ & 2 & $\underset{(<0.01)}{1.5418} \times 10^{5}$ & $\begin{array}{l}4735.4 \\
\quad(<0.01)\end{array}$ & $\begin{array}{l}7278.4 \\
(<0.01)\end{array}$ & $\begin{array}{l}2181.9 \\
(<0.01)\end{array}$ \\
\hline Error & 19 & 14,238 & 117.6 & 689.8 & 56.4 \\
\hline
\end{tabular}

${ }^{1}$ Indicates 3 replicates performed on different days.

${ }^{2}$ Manufacture of process cheese and process cheese food by Blentech twin-screw pilot-scale cooker (BTS), rapid visco analyzer-short manufacturing time (RVA-ST), and rapid visco analyzer-long manufacturing time (RVA-LT) methods. 
Table 4. Mean, relative standard deviation (RSD) from the mean ( $\mathrm{n}=3$ for RVA-ST and RVA-LT), and relative deviation (RD) from the mean ( $\mathrm{n}=2$ for BTS) values of the time of emulsification and the functional properties of process cheese food.

\begin{tabular}{|c|c|c|c|c|c|c|c|c|c|c|c|c|c|c|c|c|}
\hline \multirow{2}{*}{ Replicate no. } & \multicolumn{4}{|c|}{$\begin{array}{c}\text { Time of emulsification } \\
\text { (min) }\end{array}$} & \multicolumn{6}{|c|}{ TPA-hardness, $\mathrm{N}$} & \multicolumn{6}{|c|}{ Hot apparent viscosity, $\mathrm{cP}$} \\
\hline & \multicolumn{2}{|c|}{$\mathrm{RVA}_{\mathrm{ST}}{ }^{1}$} & \multicolumn{2}{|c|}{ RVA-LT ${ }^{2}$} & \multicolumn{2}{|c|}{ RVA-ST } & \multicolumn{2}{|c|}{ RVA-LT } & \multicolumn{2}{|c|}{$\mathrm{BTS}^{3}$} & \multicolumn{2}{|c|}{ RVA-ST } & \multicolumn{2}{|c|}{ RVA-LT } & \multicolumn{2}{|c|}{ BTS } \\
\hline 1 & 2.2 & 5.17 & 2.2 & 2.66 & 82 & 3.71 & 85 & 2.97 & 69 & 1.13 & 539 & 5.29 & 528 & 3.22 & 502 & 1.13 \\
\hline 2 & 2.1 & 0.00 & 2.1 & 0.00 & 101 & 4.01 & 106 & 0.55 & 64 & 28.72 & 466 & 4.19 & 512 & 2.84 & 469 & 5.89 \\
\hline 3 & 2.1 & 2.71 & 2.2 & 4.55 & 111 & 2.61 & 109 & 3.30 & 71 & 3.98 & 539 & 5.29 & 591 & 1.44 & 471 & 2.25 \\
\hline
\end{tabular}

${ }^{\mathrm{a}, \mathrm{b}, \mathrm{c}}$ Means with same superscript are not significantly different at $P>0.05$.

${ }^{1}$ RVA-ST $=$ Rapid visco analyzer-short manufacturing time.

${ }^{2}$ RVA-LT $=$ Rapid visco analyzer-long manufacturing time.

${ }^{3} \mathrm{BTS}=$ Blentech twin-screw pilot-scale cooker.

The failure of PCF replicate 2 to follow the trend in TPA-hardness can be attributed to a high RD for BTS treatments, indicating a large variation in TPA-hardness values between duplicate batches of PCF in BTS. However, a similar trend was not observed with respect to the hot apparent viscosity values for PC and PCF. This indicates that melted textural properties might be more sensitive to changes in processing conditions compared with the unmelted texture properties such as firmness.

Variation within a replicate. As indicated earlier, the range of RSD (RD in the case of BTS treatment) among the 3 replicates for both functional properties (TPA-hardness and hot apparent viscosity) were similar for the RVA and BTS treatments for PC (Tables 2 and 4). However, the range for RSD/RD was lower for PCF produced in the RVA compared with the BTS, which indicates that less variability in the manufacturing process was achieved during PCF manufacture in the RVA compared with the BTS.

Effect of experimental methodology. Significant differences in TPA-hardness and hot apparent viscosity (Table 3) of PC and PCF manufactured in the RVA compared with those manufactured in BTS can be partly attributed to the differences in preparation of the ingredient blends. Although the source of the natural cheese and other ingredients used were the same within each replicate for PC and PCF, the same preblend was not used when manufacturing process cheese in BTS and RVA. This could cause additional variability in the process cheese produced. Moreover, the methodology used for preblend preparation for RVA treatments was different from that used for the BTS treatment. Another important consideration is the difference in the methodology involved in the sample preparation of process cheese for TPA analysis. Irregularities in sample dimensions can lead to inconsistencies in texture mea- surements of a food product. For BTS, the cheese cylinders were cut from the 1-kg block of process cheese using a cork borer, whereas, for RVA processing, the molten process cheese was poured into cylindrical molds; there were marked differences observed in the BTS samples, such as deformation of the edges (due to the use of the cork borer) and barreling, compared with the RVA samples.

Effect of cooking conditions. The higher values of TPA-hardness and hot apparent viscosity of the processed cheese made in the RVA compared with BTS (Tables 2 and 4) indicate that the products made in the RVA were firmer in texture and less flowable or meltable than the products made in the BTS. These differences in the functional properties of process cheese may be attributed to differences in the timeshear effect (strain history) that the process cheeses underwent during manufacture. Previous research has demonstrated that an increase in strain history changed the functionality of process cheese and reduced its meltability (Glenn et al., 2003). Theories proposed by Berger et al. (1998) indicate that an increase in shear rate helps to strengthen the process cheese emulsion during manufacture. Process cheeses are subjected to different strain levels when manufactured in different cookers, depending on cooker geometry, impeller speed, and the time for which the shear was applied. Strain history $(\Gamma)$ measures the amount of strain and stress that a product undergoes during processing, independent of cooker geometry and temperature (Glenn et al., 2003). Strain history can be calculated by the following equation:

$$
\text { Strain history }(\Gamma)=\left(k^{\prime}\right)(\mathbf{M})(\mathrm{t}) \text {, }
$$

where $k^{\prime}$ refers to the mixer viscometry constant (1/ rev), $\mathrm{M}$ is the mixing rate in rpm, and $\mathrm{t}$ is the total 
processing time in min. Researchers have estimated average $k^{\prime}$ for RVA to be $20.1 /$ rev between 60 to 210 rpm (Lai et al., 2000). An average $k^{\prime}$ of $16.1 /$ rev has been reported for helical ribbon impellers similar to the BTS cooker used in this study (Glenn et al., 2002). Based on these $k^{\prime}$ values, the calculated strain history was higher in the RVA compared with the pilot plant cooker (data not shown). However, the $k^{\prime}$ values used are estimates, and the value of $20.1 / \mathrm{rev}$ is valid between 60 and $210 \mathrm{rpm}$, but an rpm value of $500 \mathrm{rpm}$ for the RVA was used in this study. If the calculated strain histories are assumed to be correct, then significant differences in the functionality of the batches produced in the RVA compared with those produced in BTS might be due to difference in the strain histories of the process cheeses.

Additionally, the PC and PCF manufactured using RVA-LT had higher hot apparent viscosity (i.e., less flowable) than those manufactured using RVA-ST. Again, this increase in hot apparent viscosity may be a result of the increase in the strain history applied in the RVA-LT compared with the RVA-ST treatments (Glenn et al., 2003). Researchers have indicated that an increase in cook time decreased the meltability of process cheese (Rayan et al., 1980).

Another factor that might influence the functional properties of process cheese would be the thermal history of process cheese in the cooker. Thermal history $(\Phi)$ is an indicator of the time-temperature effect that process cheese undergoes when manufactured (Glenn et al., 2003). Although exact product temperature at each instant during cooking was not calculated in this study, the process cheese manufactured in the RVA and in the pilot plant (BTS) might have been subjected to different thermal histories.

\section{CONCLUSIONS}

Process cheese and PCF were successfully manufactured and analyzed on a small-scale using an RVA. However, PC and PCF produced on a pilot scale (BTS) were significantly different from process cheese produced in the RVA. The RVA manufacturing time influenced process cheese functionality and weight loss during manufacture. Further research aimed at modification and standardization of the RVA methodology needs to be pursued, for example, standardizing the preblend preparation and handling for the RVA and BTS manufacturing processes and identifying RVA manufacturing profiles that match the shear input of the BTS process. Moreover, alternate paddle designs for process cheese manufacture in RVA should also be investigated.

\section{REFERENCES}

Atherton, H. V., and J. A. Newlander. 1977. Tests for fat: Babcock, Gerber, and Mojonnier. Pages 71-116 in Chemistry and Testing of Dairy Products. 4th ed. AVI Publishing Co. Inc., Westport, CT.

Berger, W., H. Klostmeyer, K. Merkenich, and G. Uhlmann. 1998. Processed Cheese Manufacture, A JOHA Guide. BK Ladenberg, Ladenberg, Germany.

Bradley, R. L., Jr., and M. A. Vanderwarn. 2001. Determination of moisture in cheese and cheese products. J. AOAC 84:570-592.

Breene, W. M. 1975. Application of texture profile analysis to instrumental food texture evaluation. J. Texture Stud. 6:53-82.

Caric, M., M. Gantar, and M. Kalab. 1985. Effects of emulsifying agents on the microstructure and other characteristics of processed cheese-A review. Food Microstruct. 4:297-312.

Drake, M. A., P. D. Gerard, V. D. Truong, and C. R. Daubert. 1999. Relationship between instrumental and sensory measurements of cheese texture. J. Texture Stud. 30:451-476.

Ennis, M. P., M. M. O'Sullivan, and D. M. Mulvihill. 1998. The hydration behaviour of rennet caseins in calcium chelating salt solution as determined using a rheological approach. Food Hydrocolloids 12:451-457.

FDA. 2003. 21 CFR, Part 133.169: Pasteurized process cheese. Food and Drug Administration, Department of Health and Human Services, Washington, DC.

Glenn, T. A., III, and C. R. Daubert. 2002. A mixer viscometry approach for blending devices. J. Food Process. Eng. 26:1-16.

Glenn, T. A., III, C. R. Daubert, B. E. Farkas, and L. A. Stefanski. 2003. A statistical analysis of creaming variables impacting processed cheese melt quality. J. Food Qual. 26:299-321.

Gupta, S. K., C. Karahdian, and R. C. Lindsay. 1984. Effect of emulsifier salts on textural and flavor properties of processed cheeses. J. Dairy Sci. 67:764-778.

Hong, Y.-H. 1989. Influences of ingredients and melting temperature on the physicochemical properties of processed cheese. Korean J. Food Sci. Technol. 21:710-713.

Hong, Y.-H. 1990. Physicochemical and textural characteristics of processed cheese manufactured with different kinds and quantities of ingredients. Korean J. Anim. Sci. 32:406-412.

Kosikowski, F. V., and V. V. Mistry. 1997. Processed cheese and related products. Pages 156-161 in Cheese and Fermented Milk Foods. Vol. 2. 3rd ed. F. V. Kosikowski, LLC, Westport, CT.

Lai, K. P., J. F. Steffe, and P. K. W. Ng. 2000. Average shear rates in the Rapid Visco Analyser (RVA) mixing system. Cereal Chem. 77:714-716.

Lee, S. K., R. J. Buwalda, S. R. Euston, E. A. Foegeding, and A. B. McKenna. 2003. Changes in the rheology and microstructure of processed cheese during cooking. Lebensm. Wiss. Technol. 36:339-345.

Lee, S. K., and H. Klostmeyer. 2001. The effect of pH on the rheological properties of reduced-fat model processed cheese spreads. Lebensm. Wiss. Technol. 34:288-292.

Lucey, J. A., M. E. Johnson, and D. S. Horne. 2003. Invited review: Perspectives on the basis of the rheology and texture properties of cheese. J. Dairy Sci. 86:2725-2743.

Marchesseau, S., and J.-L. Cuq. 1995. Water-holding capacity and characterization of protein interactions in processed cheese. J. Dairy Res. 62:479-489.

Metzger, L. E. 2003. Nutrition labeling using a computer program. Pages 1-6 in Food Analysis Laboratory Manual. S. S. Nielsen, ed. Kluwer Academic, New York.

Metzger, L. E., R. Kapoor, L. A. Rosenberg, and P. Upreti. 2002. RVA: Processed cheese manufacture. Aust. J. Dairy Technol. 57:136. (Abstr.)

Piska, I., and J. Štětina. 2003. Influence of cheese ripening and rate of cooling of the processed cheese mixture on rheological properties of processed cheese. J. Food Eng. 61:551-555.

Rayan, A. A., M. Kalab, and C. A. Ernstrom. 1980. Microstructure of processed cheese. Scan. Electron Microsc. III:635-643.

Rosenberg, L. A., and L. E. Metzger. 2003. Comparison of the melting properties of processed cheese using a Rapid Visco Analyzer (RVA) and the Schreiber melt test. J. Dairy Sci. 86. (Suppl. 1):40. (Abstr.) 
Rosenberg, L. A., L. E. Metzger, M. R. Acharya, and V. V. Mistry. 2002. Evaluation of process cheese melting characteristics using a Rapid Visco Analyzer. Page 23 in Book of Abstracts, 2002 IFT Annual Meeting and Food Expo, Anaheim, CA.

Shimp, L. A. 1985. Processed cheese principles. Food Technol. 39:63$64,66,68,70$

Sood, S. M., D. K. Gaind, and R. K. Dewan. 1979. Correlation between micelle solvation and calcium content. N.Z. J. Dairy Sci. Technol. $14: 32-34$.
Thomas, M. A. 1973. The Manufacture of Processed Cheese - Scientific Principles. 1st ed. New South Wales Department of Agriculture, Richmond, Australia.

Vakaleris, D. G., N. F. Olson, and W. V. Price. 1962. Effects of proteolysis of natural cheese on body and melting properties of pasteurized processed cheese spread. J. Dairy Sci. 45:492-494.

Zehren, V. L., and D. D. Nusbaum. 2000. Processed Cheese. 2nd ed. Cheese Reporter Publishing Co. Inc., Madison, WI. 